\title{
Effects of Caffeine and Coffee on Incident Heart Failure in General Population. Role of the CYP1A2 -163C>A Polymorphism
}

\author{
Edoardo Casiglia, Valérie Tikhonoff, Federica Albertini, Martina Montagnana, \\ Elisa Danese, Alberto Mazza, Jacopo Favaro, Francesco Finatti, Marco Benati, \\ Lucia Dal Maso, Federica Gasparotti, Paolo Spinella, Paolo Palatini
}

\begin{abstract}
This study investigates in epidemiological setting the effects of chronic caffeine and coffee intake on incident heart failure (HF) across the $-163 \mathrm{C}>\mathrm{A}$ polymorphism of CYP1A2 gene, mediating caffeine metabolism. We studied 1,475 unselected subjects from general population aged 60.0 \pm 16.7 years, genotyped for CYP1A2 $-163 \mathrm{C}>\mathrm{A}$ polymorphism and divided into fast (AA homozygous) and slow (C-carriers) caffeine metabolizers. Daily caffeine intake was calculated from a questionnaire and a dietary diary. Events due to $\mathrm{HF}$ were recorded during a 12-year follow-up. Multivariate Cox regression adjusted for confounders was used for statistical analysis. In the whole cohort, HF incidence decreased with increasing caffeine intake (hazard ratio, HR, $0.998,95 \%$ confidence intervals, $C I, 0.996-0.999, p=0.02)$. After stratifying by sex and genotype, this effect was still detectable in C-carrier men only (OR 0.994, CI 0.990-0.998, p=0.01). No effect was observed in women and in AA men. Cox estimates were significantly higher for coffee than for caffeine both in the whole cohort and in C-carrier men. At a population level, caffeine intake is protective against $\mathrm{HF}$ occurrence in slowmetabolizer men, and innocuous in other subjects. The protective effect of coffee is greater than that of mere caffeine.
\end{abstract}

Index Terms - caffeine, heart failure, CYP1A2 -163C $>\mathrm{A}$, population

Edoardo Casiglia, Department of Medicine, University of Padua, Padua, Italy

Valérie Tikhonoff, Department of Medicine, University of Padua, Padua, Italy

Federica Albertini, School of Emergency Medicine, Department of Medicine, University of Padua, Padua, Italy

Martina Montagnana, Department of Neurosciences, Biomedicine and Movement, University of Verona, Verona, Italy

Elisa Danese, Department of Neurosciences, Biomedicine and Movement, University of Verona, Verona, Italy

Alberto Mazza, Department of Medicine, Hospital of Rovigo, Rovigo, Italy

Jacopo Favaro, School of Medicine, University of Padua, Padua, Italy

Francesco Finatti, School of Medicine, University of Padua, Padua, Italy

Marco Benati, Department of Neurosciences, Biomedicine and Movement, University of Verona, Verona, Italy

Lucia Dal Maso, Department of Medicine, University of Padua, Padua, Italy

Federica Gasparotti, Department of Medicine, University of Padua, Padua, Italy

Paolo Spinella, Department of Medicine, University of Padua, Padua, Italy

Paolo Palatini, Department of Medicine, University of Padua, Padua, Italy

\section{INTRODUCTION}

Coffee is the second most consumed beverage after water, and caffeine - its main active component - is the most used recreational compound worldwide [1]. Some studies were conducted by administering coffee or caffeine to volunteers in experimental setting [2,3], but such experiments cannot answer the question about the possible effects of long-term intake of coffee or caffeine in everyday life. Some epidemiological studies tried to associate coffee consumption to the occurrence of particular conditions or events [4-10]. Their results were in the majority of cases disappointing or frankly contrasting [6,7].

Incidence of heart failure (HF) in relation to caffeine or coffee consumption has been limitedly studied, very rarely in subjects from general population [11]-[13] and never taking into account the genetic control of caffeine fate in human body, which is largely determined by the $-163 C>A$ polymorphism of the CYP1A2 gene codifying for the CYP1A2 enzymatic protein [14]. This polymorphism can not be disregarded [15], as it has been shown than the effects of caffeine can be very different in the so-called "fast metabolizers" (AA homozygous) and "slow metabolizers" (carrying the $\mathrm{C}$ allele) [16]. Fortunately, these two categories are almost equally represented in general population, allowing good statistical analysis.

The present study is aimed at investigating in epidemiological setting 1) if caffeine intake influences the incidence of HF, 2) if the effects of coffee are different from those of mere caffeine, and 3) if these effects depend on the $-163 C>A$ polymorphism of the CYP1A2 gene. For these purposes, the setting represented by a large population-based epidemiological study was chosen.

\section{METHODS}

\section{A. Study cohort and general protocol}

The study cohort was represented by 1,475 unselected men and women aged $60.0 \pm 16.7$ years (range 19.4 to 93.9) living in an area of about $550 \mathrm{~km}^{2}$ in North-East Italy and sharing homogeneous lifestyle [17], randomly taken from general population in the frame of a population-based epidemiological study whose protocol has been diffusely described elsewhere [17-21]. In brief, all adults of the above-mentioned geographic area identified through the Register's Office were called by letter, and 1,475 of them adhered to the protocol, gave informed consent and were recruited and screened by a sole staff in ad hoc surgeries. 
Height (in $\mathrm{m}$ ) and weight (in $\mathrm{kg}$ ) were measured using mechanical devices, with the subjects wearing light indoor clothing and no shoes [22]. Body mass index was calculated in $\mathrm{kg} / \mathrm{m}^{2}$ from the weight / squared height ratio. Left ventricular hypertrophy was diagnosed on the basis of the Sokolow-Lyon or Cornell criteria [23],[24]. All subjects underwent a Rose's questionnaire [25] concerning personal data, lifestyle, smoking, quality of life and personal and familial anamnesis. Diabetes [26] and the New York Heart Association (NYHA) class [27] were determined according to current guidelines.

Blood pressure was measured in triplicate by trained medical doctors by means of an automatic device. The last measurement was used in data analysis to minimize any alarm reaction.

Daily caffeine intake was calculated adding that deriving from coffee, tea, chocolate and cola [14] examining both the anamnestic report at the screening and a 7-day dietary diary. Mean individual amount of daily caffeine (mg/day) taken in normal life was used in statistical analysis. According to the same dietary questionnaires, intake of ethanol (g/day) was calculated [21] adding that deriving from wine, beer, liquors and aperitifs. The number of cigarettes smoked per day was ascertained from a questionnaire. This was necessary because both ethanol and smoke are known to influence the expression of CYP1A2 gene [28].

\section{B. Assessment of events}

Incidence of cardiovascular events was obtained from the Italian Register's Office according to the international standardized classifications commonly used for epidemiological purposes, and double-checked by referring to hospitals, retirement homes or physicians' files. Fatal and non-fatal events due to HF were defined according to the World Health Organization International Statistical Classification of Diseases-10 (ICD-10), using the codes from I50.1 to I50.4, or I50.9.

\section{Ethics}

The investigation conformed to the Declaration of Helsinki and institutional guidelines, and was approved by the Ethics Committees of the University of Padua, of the University Hospital of Verona, and of the Local Health Units No. 4 and No. 20 of the Veneto Region (Italy). Each subject gave and signed informed consent including treatment of genetic data.

\section{Genotyping}

At screening, $6 \mathrm{ml}$ of whole blood were collected in EDTA tubes for the determination of genotype. DNA was extracted using MagNA Pure 96 DNA and viral NA small volume and large volume kits, according to the protocol provided by the manufacturer (Roche Diagnostics $\mathrm{GmbH}$, Penzberg, Germany). Primers and probes for specific allelic discrimination analysis of CYP1A2 polymorphism were included in the Polymerase Chain Reaction (PCR) assay. The primers and probes used were as follows: forward primer 5'-TTT CCA gCT CTC AgA TTC TgT gAT, reverse primer 5'-ggA TAC CAg AAA gAC TAA gCT CCA TC, CYP1A2*1F probe 5' 6FAM-TCT gTg ggC ACA ggA CgC ATg g, CYP1A2*1A probe 5' HEX-CTC TgT ggg CCC Agg ACg CAT as described by dbSNP reference number (rs762551) [29]. Purified DNA was amplified in a real-time PCR reaction in the LightCycler 480 with Gene Scanning software version 1.5.1 Roche. All the reactions were performed in 96-well plates. Positive controls, genotyped by direct sequencing, were included in each run, together with a negative control containing no DNA template. TaqMan reactions were thermocycled as follows: $95^{\circ} \mathrm{C}$ in preincubation, 45 cycles at $95^{\circ} \mathrm{C}$ for primer-dependent amplification and $66.5^{\circ} \mathrm{C}$ for annealing.

\section{E. Statistics}

Preliminary power analysis showed that 329 subjects per cell were sufficient to show effects with a power of 0.90 and a test level of 0.10 for $\beta$ error and of 0.05 for $\alpha$ error, assuming a putative difference of 7 percent points in HF incidence between highest and lowest caffeine consumers. This difference was chosen a priori on the basis of on preliminary tests performed in our Laboratory, as to our knowledge no data on the effects of increasing daily doses of caffeine on HF in general population are available in literature. Therefore, the cohort of 1,475 subjects recruited for the present study appeared to be adequate also after stratification into quartiles of 369 cases each. Linearity assumption of continuous variables was ascertained for each variable by the residuals method and normality assumption by the Kolmogorov-Smirnov one-sample test.

Continuous variables were expressed as mean \pm standard deviation, and compared with analysis of variance. Preliminary logarithmization was preformed for those that were putatively not independent from each other. Continuous variables were compared with the analysis of variance and categorical variables with the $\chi^{2}$ test.

Cox proportional hazard model was used to find the variables having a prognostic role on HF incidence $(<0.10$ to enter and remove) and to calculate the hazard ratios (HR) with $95 \%$ confidence intervals (CI). An exploratory analysis of the full model demonstrated that age, sex, ethanol intake, smoking, diabetes, systolic and diastolic blood pressure, heart rate, waist-to-hip ratio, left ventricular hypertrophy, NYHA class and history of HF were potential predictors of incident HF during the follow-up. They were therefore used as covariables in the Cox models, together with daily caffeine intake or - separately - with daily servings of coffee.

As the $-163 C>A$ polymorphism of CYP1A2 gene notoriously controls the metabolism and therefore the effects of caffeine [1],[14], an interaction term between caffeine intake and genotype was introduced as a covariable in the above-mentioned multiple analyses. According to current literature [30],[31], subjects carrying the $\mathrm{C}$ allele (Ccarriers) were considered together both in univariate analysis for comparison to AA homozygous and in multivariate analysis for the determination of the predictors of incident HF. As sex was a significant predictor, Cox analyses were also performed including the dichotomic covariable «Ccarrier or AA homozygous» separately in men and women. 


\section{RESULTS}

\section{A. Univariate descriptive statistics}

Characteristics of the cohort. The general characteristics of the cohort, also stratified by sex, are shown in Table 1. Caffeine intake was in average $240.3 \pm 116.4 \mathrm{mg} /$ day and came from coffee for $89.1 \%(214.1 \pm 109.5 \mathrm{mg} /$ day in average, CI 208.5 to 219.7$)$, from tea for $10.2 \%$ (24.6 437.1 $\mathrm{mg}$ /day in average, CI 21.6 to 15.4 ), and from other sources (chocolate or cola) for $0.7 \%(1.4 \pm 3.9 \mathrm{mg} /$ day in average, $\mathrm{CI}$ 1.2 to 1.6$)$.

Table 1. General characteristics of the population, also stratified by sex. Mean \pm standard deviation (95\% confidence intervals in brackets). NYHA: New York Heart Association; BP: arterial blood pressure; HF: heart failure: LVH: left ventricular hypertrophy.

\begin{tabular}{|c|c|c|c|}
\hline Items & $\begin{array}{c}\text { All } \\
(n=1,475)\end{array}$ & $\begin{array}{c}\text { Men } \\
(n=669)\end{array}$ & $\begin{array}{c}\text { Women } \\
(n=806)\end{array}$ \\
\hline Age (years) & $\begin{array}{c}60.0 \pm 16.7 \\
(59.2-60.9)\end{array}$ & $\begin{array}{c}58.2 \pm 16.4 \\
(56.9-59.4)\end{array}$ & $\begin{array}{c}61.5 \pm 16.9 \\
(60.4-62.7)\end{array}$ \\
\hline NYHA class & $\begin{array}{l}1.12 \pm 0.45 \\
(1.10-1.15)\end{array}$ & $\begin{array}{c}1.09 \pm 0.40 \\
(1.06-1.12)\end{array}$ & $\begin{array}{c}1.15 \pm 0.49 \\
(1.12-1.19)\end{array}$ \\
\hline Waist-to-hip ratio & $\begin{array}{c}0.90 \pm 0.09 \\
(0.89-0.90)\end{array}$ & $\begin{array}{c}0.93 \pm 0.08 \\
(0.93-0.94)\end{array}$ & $\begin{array}{c}0.87 \pm 0.08 \\
(0.86-0.87)\end{array}$ \\
\hline $\begin{array}{l}\text { Systolic BP } \\
(\mathrm{mmHg})\end{array}$ & $\begin{array}{c}156.1 \pm 26.1 \\
(154.7-157.4)\end{array}$ & $\begin{array}{l}155.9 \pm 24.0 \\
(154-157.8)\end{array}$ & $\begin{array}{c}156.2 \pm 27.7 \\
(154.2-158.1)\end{array}$ \\
\hline $\begin{array}{l}\text { Diastolic BP } \\
(\mathrm{mmHg})\end{array}$ & $\begin{array}{c}88.3 \pm 11.4 \\
(87.7-88.9)\end{array}$ & $\begin{array}{c}89.8 \pm 10.9 \\
(89.0-90.7)\end{array}$ & $\begin{array}{c}87.0 \pm 11.6 \\
(86.2-87.9)\end{array}$ \\
\hline $\begin{array}{l}\text { Heart rate } \\
\text { (bpm) }\end{array}$ & $\begin{array}{c}69.4 \pm 10.6 \\
(68.9-69.9)\end{array}$ & $\begin{array}{c}67.2 \pm 10.5 \\
(66.4-68.0)\end{array}$ & $\begin{array}{l}71.2 \pm 10.3 \\
(70.5-71.9)\end{array}$ \\
\hline $\begin{array}{l}\text { Smoking } \\
\text { (cigarettes/day) }\end{array}$ & $\begin{array}{c}1.6 \pm 4.5 \\
(1.3-1.8)\end{array}$ & $\begin{array}{l}2.2 \pm 5.6 \\
(1.8-2.6)\end{array}$ & $\begin{array}{c}1.0 \pm 3.1 \\
(0.8-1.2)\end{array}$ \\
\hline $\begin{array}{l}\text { Ethanol intake } \\
\text { (g/day) }\end{array}$ & $\begin{array}{c}27.0 \pm 31.6 \\
(25.4-28.6)\end{array}$ & $\begin{array}{c}43.5 \pm 38.4 \\
(40.6-46.4)\end{array}$ & $\begin{array}{c}13.3 \pm 13.8 \\
(12.4-14.3)\end{array}$ \\
\hline $\begin{array}{l}\text { Caffeine intake } \\
(\mathrm{mg} / \text { day) }\end{array}$ & $\begin{array}{c}240.3 \pm 116.4 \\
(234.4-246.3)\end{array}$ & $\begin{array}{c}241.3 \pm 117 \\
(232.4-250)\end{array}$ & $\begin{array}{c}239.5 \pm 115.8 \\
(231.5-247.5)\end{array}$ \\
\hline $\begin{array}{l}\text { History of HF } \\
(0: \text { no; } 1: \text { yes })\end{array}$ & $38(2.58 \%)$ & $23(3.44 \%)$ & $15(1.86 \%)$ \\
\hline $\begin{array}{l}\text { LVH } \\
\text { (0: no; } 1 \text { : yes) }\end{array}$ & $714(52.50 \%)$ & $\begin{array}{c}308 \\
(50.91 \%)\end{array}$ & $406(53.77 \%)$ \\
\hline $\begin{array}{l}\text { Diabetes } \\
(0: \text { no; } 1: \text { yes })\end{array}$ & $279(18.9 \%)$ & $138(20.6 \%)$ & $141(17.5 \%)$ \\
\hline
\end{tabular}

CYP1A2/-163C $>A$ polymorphism. In the whole population the distribution of the $-163 C>A$ polymorphism of CYP1A2 gene was AA 44.1\%, AC $43.3 \%$ and CC $12.6 \%$ and respected the Hardy-Weinberg equilibrium. After stratification by sex, the distribution was $46.9 \%$ AA, $40.4 \%$ $\mathrm{AC}$ and $12.7 \% \mathrm{CC}$ in men, and $41.7 \% \mathrm{AA}, 45.8 \% \mathrm{AC}$ and $12.5 \% \mathrm{CC}$ in women. The C-carriers were 825 (55.9\% of the whole cohort), i.e. 470 women and 355 men.

Incidence of $H F$. Incident events are summarized in Table 2. During the 12 years of follow-up, 125 new cases of HF were recorded $(8.5 \%)$. Incidence of HF was similar in men $(8.8 \%)$ and women $(8.2 \%, \mathrm{p}=0.7)$, and higher in subjects labelled as having history of $\mathrm{HF}$ in comparison to those free from this trait $(18.4 \%$ vs. $8.2 \%, \mathrm{p}<0.05)$. Independent of caffeine and coffee consumption, incidence of HF was similar in the AA and in the C-carriers (9.4 vs. $7.7 \%$, $\mathrm{p}=0.26$ ).

Table 2. Incidence of non-fatal and fatal cardiovascular events. Percents in brackets. CAD: coronary artery disease; TIA: transient ischaemic attack.

\begin{tabular}{lrcccr}
\hline \multicolumn{1}{c}{$\begin{array}{c}\text { Cardiovascular } \\
\text { events }\end{array}$} & \multicolumn{5}{c}{ All $(n=1,475)$} \\
\cline { 2 - 6 } All & $695(47.1)$ & $557(37.8)$ & $138(9.3)$ \\
Heart failure & 125 & $(8.5)$ & 100 & $(6.8)$ & $25(1.7)$ \\
Arterial hypertension & 136 & $(9.2)$ & 134 & $(9.1)$ & 2 \\
CAD & 136 & $(9.2)$ & 80 & $(5.4)$ & $56(3.8)$ \\
Stroke or TIA & 103 & $(7.0)$ & 71 & $(4.8)$ & $32(2.2)$ \\
Dysrythmias & 110 & $(7.4)$ & 108 & $(7.3)$ & $2(0.1)$ \\
Other and minor & 85 & $(5.8)$ & 64 & $(4.4)$ & $21(1.4)$ \\
\hline
\end{tabular}

Effects of caffeine and coffee. Considering caffeine deriving from any source and independent of the genetic pattern, HF incidence decreased with increasing daily caffeine intake (Figure 1, upper panel; $\mathrm{p}<0.00001$ ).

Considering coffee consumption instead of intake of caffeine from any source, HF incidence decreased with increasing daily servings of coffee (Fig. 1, lower panel; $\mathrm{p}<0.0001)$.

Incidence of HF was not associated to intake of tea, chocolate and cola (data not show).
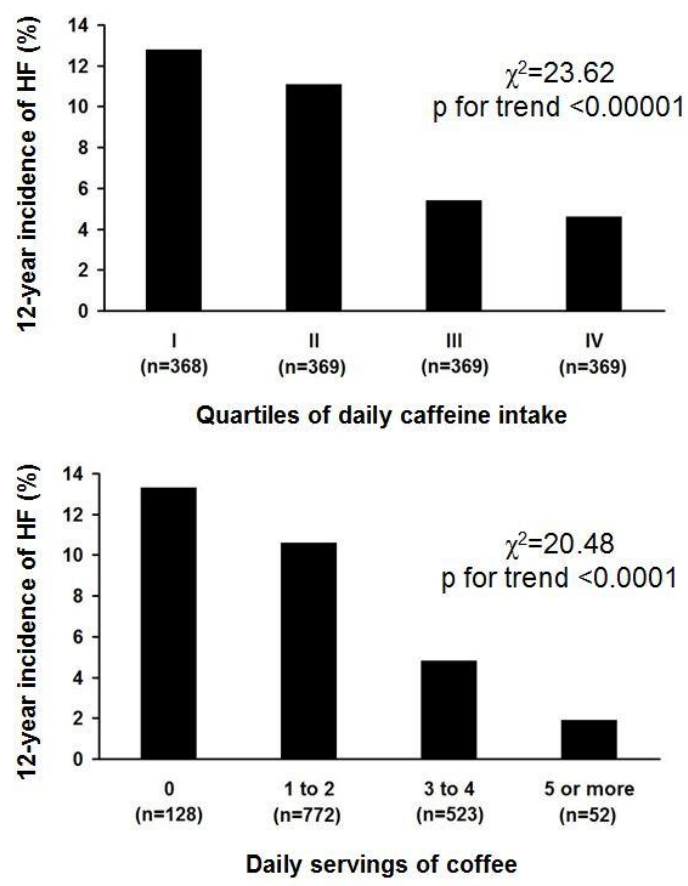

Fig. 1. Incident heart failure by quartiles of caffeine (upper panel) and by cups of coffee (lower panel). A significant trend towards lower incidence is observed with increasing daily caffeine or coffee intake.

\section{B. Multivariate statistics}

Cox analysis for any-source caffeine. Caffeine intake had a protective effect on incident $\mathrm{HF}$ in the whole population (OR 0.998, CI 0.996 to $0.999, \mathrm{p}=0.02$ ). An interaction term between caffeine and the variable «C-carrier or AA homozygous» was accepted in the equation (HR 1.0008, CI 
1,0002 to $0.0014, \mathrm{p}<0.02$ ); sex resulted to be a significant predictor of HF as well (HR 1.915, CI 1.220 to 3.008, $\mathrm{p}<0.005)$. After stratifying according to sex and genotype, a protective effect of caffeine against $\mathrm{HF}$ was detectable in $\mathrm{C}$ carrier men, but neither in $\mathrm{C}$-carrier women nor in AA homozygous independent of sex (Fig. 2). Attention was therefore focused on the $\mathrm{C}$-carrier men.
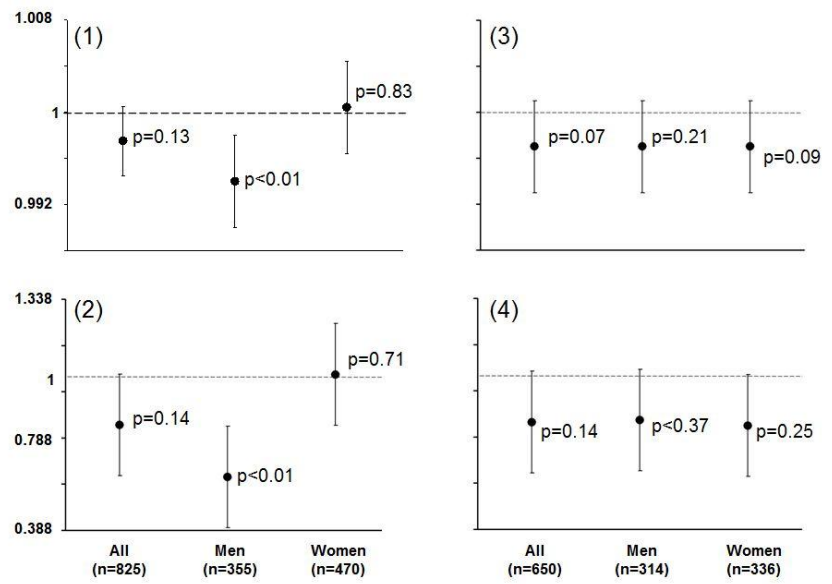

Fig. 2. Adjusted OR with $95 \%$ CI of heart failure for caffeine and coffee intake in the different genotypes. Multivariate Cox analysis had incident heart failure as dichotomic dependent variable, $\mathrm{mg}$ /day of caffeine [panel (1) in C-carriers, panel (3) in AA homozygous] or serving/day of coffee [panel (2) in C-carriers, panel (4) in AA homozygous] as independent variable, and age, sex, ethanol intake, smoking, diabetes, systolic and diastolic blood pressure, heart rate, waist-to-hip ratio, left ventricular hypertrophy, NYHA class and history of HF as confounders.

Cox analysis for coffee. When the Cox analysis was repeated using daily cups of coffee, the results were similar to those obtained for daily caffeine intake, with a protective effect of increasing coffee consumption in the entire cohort and in the C-carrier men only (Fig. 2).

By quartiles of daily caffeine intake

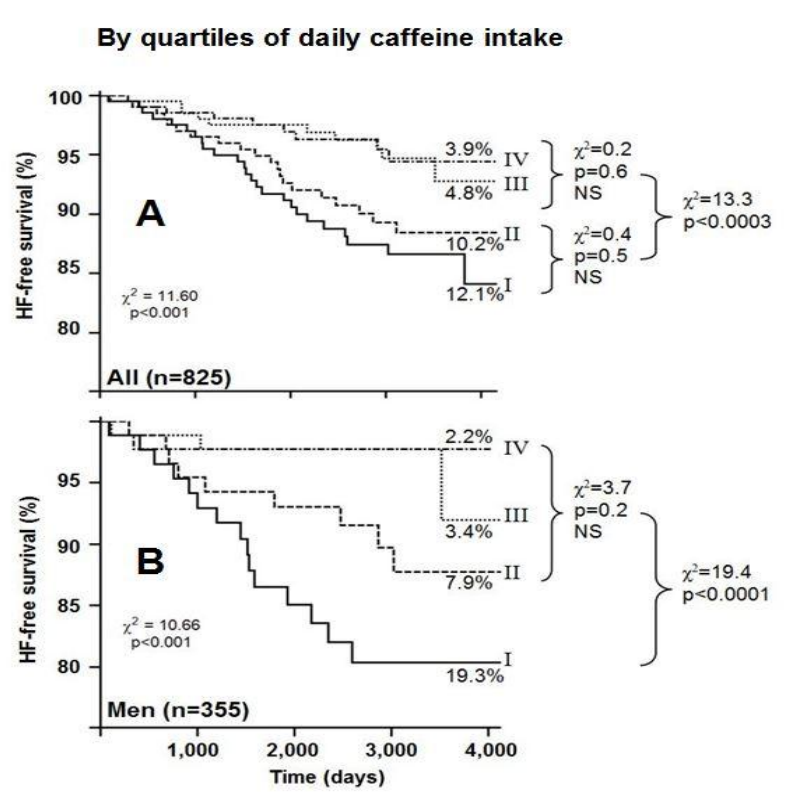

Caffeine vs. coffee. In multivariate Cox analysis the estimates of coffee consumption for the whole cohort ($0.170, \mathrm{SE}=0.089, \mathrm{p}<0.03)$ and for the $\mathrm{C}$-carrier men $(-0.476$, $\mathrm{SE}=0.182, \mathrm{p}<0.009)$ were significantly higher in absolute values than those for caffeine intake $(-0.002, \mathrm{SE}=0.001$, $\mathrm{p}<0.03$; and $-0.004, \mathrm{SE}=0.001, \mathrm{p}<0.008$, respectively).

Analysis of $C$-carriers. Fig. 3 shows the Kaplan-Meier statistics in the $\mathrm{C}$-carriers in relation to intake of caffeine (left panels) and coffee (right panels).

The upper panels include all the $\mathrm{C}$-carriers, while in the lower panels only the men are taken into account. Plausible aggregations and their statistics are indicated.

Cox analysis for tea and other sources of caffeine. When the Cox analysis was repeated using daily cups of tea or other sources of caffeine (chocolate, cola), no predictive role on incident $\mathrm{HF}$ was found, independent of the $-163 C>A$ polymorphism of the CYP1A2 gene, the only direct predictors being age, male sex, higher NYHA class and left ventricular hypertrophy (data not shown). Due to the low number of subjects consuming caffeine from these sources, no stratification by genotype was possible.

\section{DISCUSSION}

\section{A. Background}

In this unselected sample of 1,475 men and women from general population followed-up for 12 years, both caffeine and coffee intake inversely predicted incident HF. This is in line with previous papers demonstrating a protective effect of coffee [32], and in contrast with other ones showing its possible detrimental [13], neutral [33,34] or J-shaped effect [35].

Caffeine is the most represented active compound of

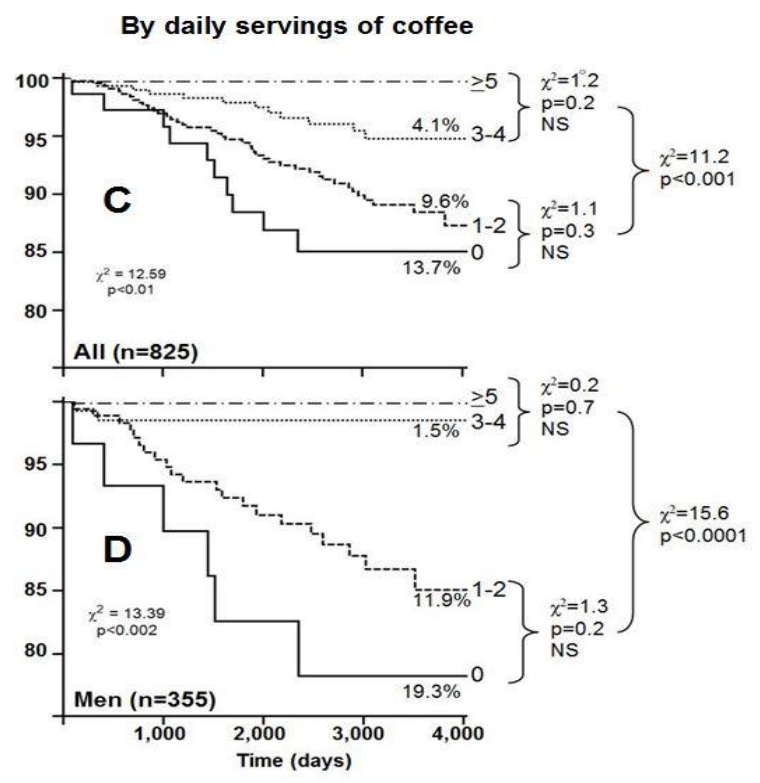

Fig. 3. Kaplan-Meier analysis in C-carriers only. Left panels. Kaplan-Meier analysis by quartiles of caffeine intake in all the 825 subjects (upper panel) and in the 355 men (lower panel). I, II, II and IV indicate the four quartiles, and percent numbers indicate, for each quartile, the 12-year incidence of heart failure. In all the C-carriers, $210 \mathrm{mg} /$ day caffeine is the cut-off separating the first 2 from the last 2 quartiles. Right panels. The same analysis by daily cups of coffee in all (upper panel) and in men (lower panel). 0, 1-2, 3-4 and $\geq 5$ indicate daily servings; \% indicate, for each line, the 12-year incidence of heart failure. $\chi^{2}$ and $\mathrm{p}$ for trend are show in the middle of the figure. Two cups/day is the cut-off separating the first two from the last two lines in both panels. 
coffee, and coffee is in turn the main source of dietary caffeine worldwide [14]. Nevertheless, whole coffee contains many other substances acting as agonists. In the study presented herein, caffeine and coffee will therefore be discussed separately.

\section{B. Caffeine}

In univariate analysis, incidence of new cases of HF decreased significantly with increasing caffeine intake from any source, passing from $12.8 \%$ in twelve years in subjects consuming $<160 \mathrm{mg} /$ day of caffeine to $4.6 \%$ in those consuming >320 mg/day. Not only this, but in multivariate analysis caffeine intake was an inverse predictor of incident HF independent of age, sex, NYHA class, diabetes, arterial blood pressure, smoking habits, ethanol intake, body adiposity, heart rate, caloric intake and even history of HF. Actually, even selecting subjects free from $\mathrm{HF}$ at initial screening did not change the model.

The fate of caffeine in the body is notoriously influenced by the $-163 C>A$ polymorphism of CYP1A2 gene, that codifies for a hepatic enzyme oxydating caffeine and accounting for about $95 \%$ of its clearance [14]. The effects of caffeine intake is therefore different across this polymorphism $[14,31,36]$. Actually, the effects of caffeine are very different in slow metabolizers (C-carriers) and in fast metabolizers (AA homozygous) [15].

In our experience, no beneficial effects of caffeine and coffee were detectable in AA subjects.

Taking into account the C-carriers, a protective effect against incident HF was only detected in men. It is likely that in slow metabolizers caffeine body pool tends to remain higher due to reduced oxidation, leading to greater effect in all organs (caffeine is widely distributed through the body [14]). Caffeine induces $\mathrm{Ca}^{++}$release from the sarcoplasmic reticulum and inhibits its reuptake [37,38]. As a consequence, the intracellular $\mathrm{Ca}^{++}$decay is slowed down. Intracellular $\mathrm{Ca}^{++}$in turns determines the activation of endothelial nitric oxide synthase, with production of higher quantities of nitric oxide, so increasing muscular contractility [39]. This effect, more evident in slow than in fast metabolizers, could hypothetically lead to chronically better heart function in the former than in the latter. On the other hand, this hypothetical mechanism cannot be the only one involved in protection against incident HF, as other recreational compounds having inotropic effect show no protective action and can on the contrary favour $\mathrm{HF}$ occurrence [40].

\section{Coffee}

Coffee contains many active compounds that, although not directly associated to heart contractility, could play a role in influencing HF occurrence.

In our experience, in univariate analysis incidence of new cases of HF during the follow-up decreased significantly with increasing coffee intake, passing from $13 \%$ in subjects abstaining from coffee to $2 \%$ in those consuming $\geq 5$ servings/day. Furthermore, in multivariate analysis, daily cups of coffee inversely predicted incident HF independent of age, sex, NYHA class, diabetes, arterial blood pressure, smoking habits, ethanol intake, body adiposity, heart rate, caloric intake and even of history of HF. This multivariate trend was limited to the C-carrier men. Selecting subjects free from HF at initial screening did not change the model. Our data therefore demonstrate that coffee consumption was not only innocuous or neutral as suggested for instance by Kelly and Granger [41] or - at a population level - by Ahmed et al. [34] and by Lopez-Garcia et al. [42], but even protective, at least in men carrying the $\mathrm{C}$ allele of $-163 C>A$ polymorphism. Other Authors occasionally found a positive effect of coffee against HF [32], but they had no information about genotype, which made their conclusions less authoritative.

Cox estimates of coffee consumption were significantly higher in absolute values than those of caffeine intake, suggesting that the protective of coffee was greater than that of caffeine. In other words, it is plausible that the additional compounds of coffee could add a surplus value, making coffee more protective than mere caffeine against incident HF.

\section{Strength and limitations}

The strength of our study is that it is population-based and it is the first one taking into consideration the CYP1A2 $163 C>A$ pattern when analyzing the effects of caffeine and of coffee on incident HF separately in men and women. A limitation is represented by the fact that Italian «espresso» coffee was consumed, so that the results could not be directly applied to other types of coffee or serving. Consumption of tea, chocolate and cola was too low to allow statistical analysis.

\section{E. Conclusions}

At a population level, caffeine is protective against $\mathrm{HF}$ occurrence in men carrying the $\mathrm{C}$ allele of $-163 C>A$ CYP1A2, and innocuous in other people. Coffee is more protective than caffeine. The results of the present study are limited to HF, and the reader must be aware that caffeine and coffee could have detrimental effects on other organs and functions $[3,9,15,43]$.

\section{V.REFERENCES}

[1] Fredholm BB, Bättig K, Holmén J, Nehlig A, Zvartau EE. Actions of caffeine in the brain with special reference to factors that contribute to its widespread use. Pharmacol Rev 1999;51:83-133.

[2] Casiglia E, Paleari CD, Petucco S, Bongiovì S, Colangeli G Baccilieri MS et al. Haemodynamic effects of coffee and purified caffeine in normal volunteers: a placebo-controlled clinical study. J Hum Hypertens 1992;6:95-99.

[3] Pizziol A, Tikhonoff V, Paleari CD, Russo E, Mazza A Ginocchio $\mathrm{G}$ et al. Effects of caffeine on glucose tolerance: a placebo-controlled study. Eur J Clin Nutr 1998;52:846-849.

[4] Palatini P, Fania C, Mos L Garavelli G, Mazzer A, Cozzio S et al. Coffee consumption and risk of cardiovascular events in hypertensive patients. Results from the HARVEST. Int J Cardiol 2016;212:131-137.

[5] Palatini P, Dorigatti F, Saladini F, Benetti E, Mos L, Mazzer A et al. Factors associated with glomerular hyperfiltration in the early stage of hypertension. Am J Hypertens 2012;25:1011-1016.

[6] Palatini P, Benetti E, Mos L, Garavelli G, Mazzer A, Cozzio S et al. Association of coffee consumption and CYP1A2 
polymorphism with risk of impaired fasting glucose in hypertensive patients. Eur J Epidemiol 2015;30:209-217.

[7] Kwok MK, Leung GM, Schooling CM. Habitual coffee consumption and risk of type 2 diabetes, ischemic heart disease, depression and Alzheimer's disease: a Mendelian randomization study. Sci Rep 2016:6:36500.

[8] Casiglia E, Spolaore P, Ginocchio G, Ambrosio GB. Unexpected effects of coffee consumption on liver enzymes. Eur J Epidemiol 1993;9:293-297.

[9] Celik T, Iyisoy A, Amasyali B. The effects of coffee intake on coronary heart disease: ongoing controversy. Int $\mathrm{J}$ Cardiol 2010;144:118

[10] Zuchinali P, Souza GC, Pimentel M, Chemello D, Zimerman A, Giaretta V et al. Short-term effects of high-dose caffeine on cardiac arrhythmias in patients with heart failure: a randomized clinical trial. JAMA Intern Med 2016;176:1752-1759

[11] Levitan EB, Ahmed HN, Mittleman MA, Wolk A. Coffee consumption and incidence of heart failure in women. Circ Heart Fail 2011;4:414-418.

[12] Wang Y, Tuomilehto J, Jousilahti P, Antikainen R, Mähönen M, Männistö $S$ et al. Coffee consumption and the risk of heart failure in Finnish men and women. Heart 2011;97:44-48.

[13] Wilhelmsen L, Rosengren A, Eriksson H, Lappas G. Heart failure in the general population of men- morbidity, risk factors and prognosis. J Intern Med 2001;249:253-261.

[14] Cappelletti S, Piacentino D, Sani G, Aromatario M. Caffeine: cognitive and physical performance enhancer or psychoactive drug? Curr Neuropharmacol 2015;13:71-88.

[15] Palatini P. Letter regarding article "Habitual coffee consumption and risk of heart failure: a dose-response meta-analysis". Circ Heart Fail 2012;5:e98.

[16] Tan EK, Chua E, Fook-Chong SM, Teo YY, Yuen Y, Tan L et al. Association between caffeine intake and risk of Parkinson's disease among fast and slow metabolizers. Pharmacogenet Genomics 2007;17:1001-1005.

[17] Tikhonoff V, Casiglia E, Guidotti F, Giordano N, Martini B, Mazza A et al. Body fat and the cognitive pattern: a populationbased study. Obesity 2015;23:1502-1510.

[18] Mazza A, Zamboni S, Rizzato E, Pessina AC, Tikhonoff V, Schiavon L et al. Serum uric acid shows a J-shaped trend with coronary mortality in non-insulin-dependent diabetic elderly people. The CArdiovascular STudy in the ELderly (CASTEL). Acta Diabetol 2007; 44:99-105

[19] Palatini P, Reboldi G, Beilin LJ, Casiglia E, Eguchi K et al. Added predictive value of night-time blood pressure variability for cardiovascular events and mortality: the Ambulatory Blood Pressure-International Study. Hypertension 2014:64:487-493.

[20] Casiglia E, Tikhonoff V, Caffi S, Boschetti G, Grasselli C, Saugo $\mathrm{M}$ et al. High dietary fiber intake prevents stroke at a population level. Clin Nutr 2013;32:811-818.

[21] Casiglia E, Tikhonoff V, Bascelli A, Giordano N, Caffi S, Andreatta $\mathrm{E}$ et al. Dietary iron intake and cardiovascular outcome in Italian women: 10-year follow-up. J Womens Health 2011;20:1565-1571.

[22] The Emerging Risk Factors Collaboration. Adult height and the risk of cause-specific death and vascular morbidity in 1 million people: individual participant meta-analysis. Int $\mathrm{J}$ Epidemiol 2012:41:1419-1433.

[23] Tikhonoff V, Casiglia E. Evolving concepts of left ventricular hypertrophy. Eur Heart J 2008;29:846-848.

[24] Casiglia E, Schiavon L, Tikhonoff V, Bascelli A, Martini B, Mazza A et al. Electrocardiographic criteria of left ventricular hypertrophy in general population. Eur $\mathbf{J}$ Epidemiol 2008;23:261-271.

[25] Rose GA, Blackburn H, Gillum RF, Prineas RJ. Cardiovascular survey methods. WHO, 1982.

[26] American Diabetes Association. Standards of medical care in diabetes. Diab Care 2016;9(Suppl.1):s1-112.

[27] Yancy CW, Jessup M, Bozkurt B, Butler J, Casey DE Jr, Drazner $\mathrm{MH}$ et al. $2013 \mathrm{ACCF} / \mathrm{AHA}$ guideline for the management of heart failure: a report of the American College of Cardiology Foundation/American Heart Association Task Force on practice guidelines. Circulation 2013;128:e240-327.

[28] Zhou SF, Wang B, Yang LP, Liu JP. Structure, function, regulation and polymorphism and the clinical significance of human cytochrome P450 1A2. Drug Metab Rev 2010;42:268354.
[29] National Center for Biotechnology Information (NCBI), dbSNP short Genetic Variations, Reference SNP (refSNP) Cluster Report: rs762551. Available at: www.ncbi.nlm.nih gov/SNP/snp_ref.cgi?searchType=adhoc_search\&type=rs\&rs=rs 762551.

[30] Sachse C, Brockmoller J, Bauer S, Roots I. Functional significance of a $\mathrm{C}$ to $\mathrm{A}$ polymorphism in intron 1 of the cytochrome P450 1A2 (CYP1A2) gene tested with caffeine. Br J Clin Pharmacol 1999;47:445-449.

[31] Cornelis MC, El-Sohemy A, Kabagambe EK, Campos H. Coffee, CYP1A2 genotype, and risk of myocardial infarction. JAMA 2006;295:1135-1141.

[32] O'Keefe JH, Bhatti SK, Patil HR, DiNicolantonio JJ, Lucan SC, Lavie CJ. Effects of habitual coffee consumption on cardiometabolic disease, cardiovascular health, and all-cause mortality. J Am Coll Cardiol 2013;62:1043-1051.

[33] Rebello SA, Van Dam RM. Coffee consumption and cardiovascular health: getting to the heart of the matter. Curr Cardiol Rep 2013;15:403-414.

[34] Ahmed HN, Levitan EB, Wolk A, Mittleman MA. Coffee consumption and risk of heart failure in men: an analysis from the Cohort of Swedish Men. Am Heart J 2009; 158:667-672.

[35] Mostofsky E, Rice MS, Levitan EB, Mittleman MA. Habitual coffee consumption and risk of heart failure: a dose-response meta-analysis. Circ Heart Fail 2012;5:401-405.

[36] Palatini P, Ceolotto G, Ragazzo F, Dorigatti F, Saladini F, Papparella I et al. CYP1A2 genotype modifies the association between coffee intake and the risk of hypertension. J Hypertens 2009;27:1594-1601.

[37] Endo M. Calcium release from the sarcoplasmic reticulum Physiol Rev 1977;57:71-108.

[38] Supinski, GS, Deal EC, Kelsen SG. The effects of caffeine and theophylline on diaphragm contractility. Am Rev Respir Dis 1984;130:429-433.

[39] Ward ML, Crossman DJ, Cannell MB. Mechanisms of reduced contractility in an animal model of hypertensive heart failure. Clin Exp Pharmacol Physiol. 2011;38:711-716.

[40] El-Menyar A, Mekkodathil A, Al-Thani H, Al-Motarreb A. Khat use: history and heart failure. Oman Med J 2015;30:77-82.

[41] Kelly JP, Granger CB. More evidence that caffeine consumption appears to be safe in patients with heart failure. JAMA Intern Med 2016;76:1759-1760.

[42] Lopez-Garcia E, Van Dam RM, Li TY, Rodriguez-Artalejo F, Hu FB. The relationship of coffee consumption with mortality. Ann Intern Med 2008;148:904-914.

[43] Kromhout D, Spaaij CJ, De Goede J, Weggemans RM. The 2015 Dutch food-based dietary guidelines. Eur J Clin Nutr 2016;70:869-878.

Edoardo Casiglia, MD, specialist in Cardiology, in Pharmacology and in Anesthesia and Intensive Care, is Professor of Internal Medicine at the University of Padova, Italy (Department of Medicine, Laboratory of Epidemiology). He published many papers on population-based epidemiology and biostatistics, and has been responsible of many epidemiological studies such as the CArdiovascular STudy in the ELderly (CASTEL), the Last Evidences Of Genetic Risk factors in the Aged (LEOGRA) and the Growing Old With Less Disease Enhancing Neurofunctions (GOLDEN) studies.

Valérie Tikhonoff, MD, PhD, specialist in Internal Medicine, research doctor in Hypertension and Vascular Biology, is a researcher at the University of Padova, Italy (Department of Medicine, Laboratory of Epidemiology). She published many papers on population-based epidemiology and biostatistics, and has been responsible of the European Project on Genes in Hypertension (EPOGH) Italian Branch and participates to many epidemiological studies with particular attention to population genetics, arterial hypertension and cardiovascular risk.

Federica Albertini, MD, is a resident in Emergency Medicine at the University of Padova, Italy. She is involved in the LEOGRA and GOLDEN studies.

Martina Montagnana, MD, specialist in Clinical Biochemistry, is Professor of Clinical Biochemistry at the Department of Neurosciences, 
Biochemistry and Movement of the University of Verona, Italy. She published many papers on metabolic syndrome, on cardiovascular risk factors, on ischaemic and neoplastic markers and on the genetics of blood pressure regulation.

Elisa Danese, Pharmaceutical Chemistry doctor, specialist in chemical biochemistry and $\mathrm{PhD}$ in Medical, Clinical and Experimental Science, is a research fellow at the Department of Neurosciences, Biochemistry and Movement of the University of Verona, Italy. She works on the biology of cancer and metabolic syndrome.

Alberto Mazza, MD, $\mathrm{PhD}$, specialist in Internal Medicine, doctor of research in Diabetology, Medical Therapy, Clinical Pharmacology and Nephrourologic Sciences, is medical director and responsible of the Centre for Arterial Hypertension at the Department of Medicine of the Hospital of Rovigo, Italy. He has been responsible of the Risk Of Vascular complications: Impact of Genetics in Old people (ROVIGO) epidemiological study and published many papers on epidemiology, arterial hypertension and cardiovascular risk.

Jacopo Favaro, MD, graduated at the University of Padova, Italy. He is involved in the GOLDEN and EPOGH studies.

Francesco Finatti is graduating at the University of Padova, Italy. He is involved in the GOLDEN study.

Marco Benati, medical biotechnician, is getting a $\mathrm{PhD}$ degree at the University of Verona, Italy, where he works for the Department of Neurosciences, Biochemistry and Movement.

Lucia Dal Maso, medical biotechnician, works as biologist at the Laboratory of Epidemiology of the Department of Medicine, University of Padova, Italy.

Federica Gasparotti, MD, is a research fellow at the University of Padova, Italy. She is involved in the LEOGRA and GOLDEN studies.

Paolo Spinella, MD, specialist in Endocrinology, in Clinical Nutrition and in Sports Medicine, is professor of Nutrition and Dietetics and director of the Postgraduation School in Clinical Nutrition at the University of Padova. He published many papers on epidemiology, mainly in the field of clinical nutrition. $\mathrm{He}$ is responsible of the NUTRI-RISK and of the NUTR_O_GEN studies.

Paolo Palatini, MD, specialist in Cardiology and in Internal Medicine, Professor of Internal Medicine at the University of Padova, Italy (Department of Medicine). He published many papers on population-based epidemiology and biostatistics, particularly in the field of heart failure, and has been responsible of the Hypertension and Ambulatory Recording Venetia Study (HARVEST). 